\title{
MODEL PEMBERDAYAAN PETANI UBIKAYU MELALUI POLA KLASTER SISTEM AGRIBISNIS TERINTEGRASI DI KABUPATEN SUKABUMI PROVINSI JAWA BARAT
}

\author{
Himmatul Miftah ${ }^{1)}$ Ahmad Syarbaini ${ }^{2)}$ \\ 1) Dosen Fakultas Pertanian Universitas Djuanda Bogor \\ ${ }^{2)}$ Dosen Fakultas Ilmu Pangan Halal Universitas Djuanda Bogor
}

\begin{abstract}
The research was aimed at developing a society empowerment model through a cluster pattern. Empowerment was able to increase income through the optimization of farming resources to produce processed cassava products with high selling and added values. The model was developed by the integration of upstream and downstream agribusiness subsystems by using a cluster pattern that involved various components including farmers/farmer groups, processes in agribusiness system, and institutional system in cassava agribusiness in Sukabumi Regency.
\end{abstract}

Key words : empowerment model, cluster pattern, added values, integration of upstream and downstream

\begin{abstract}
Abstrak: Penelitian ini bertujuan untuk menyusun model pemberdayaan masyarakat melalui pola klaster. Pemberdayaan mampu meningkatkan pendapatan melalui optimalisasi penggunaan sumberdaya usahatani sehingga produk benilai jual tinggi dan meningkatkan nilai tambah produk olahan ubikayu. Penyusunan model pemberdayaan petani ubikayu dilakukan dengan mengintegrasikan subsistem agribisnis hulu sampai hilir melalui pola klaster dengan melibatkan komponen petani/kelompok tani, proses dalam sistem agribisnis dan kelembagaan sistem agribisnis ub kayu di Kabupaten Sukabumi.
\end{abstract}

Kata kunci: model pemberdayaan ,pola klaster, nilai tambah ubikayu, integrasi hulu hilir

\section{PENDAHULUAN}

Di negara manapun tidak terkecuali di Indonesia. masalah kemiskinan merupakan salah satu persoalan mendasar yang menjadi pusat perhatian pemerintah Perkembangan jumlah dan persentase penduduk miskin pada periode 1996-2009 tampak berfluktuasi dari tahun ke tahun meskipun terlihat adanya kecenderungan menurun pada 2000-2005. Badan Pusat Statistik (BPS, 2009) jumlah penduduk miskin absolut secara nasional 37 juta jiwa atau sekitar 17,5\% dari total penduduk Indonesia (untuk tahun 2007 per maret 2008, turun menjadi sekitar 34 juta atau 14\%).

Upaya mengurangi penduduk miskin antara lain melalui melalui pemberdayaan masyarakat miskin. Keberhasilan menurunkan penduduk miskin diperlukan model pemberdayaan masyarakat yang spesifik dan terpercaya (reliable) serta tepat sasaran. Penyusunan model pemberdayaan masyarakat yang terpercaya dapat menjadi instrumen tangguh bagi petani ubikayu yang umumnya miskin membutuhkan upaya penanganan khusus. Karakteristik usahatani ubikayu yang spesifik membutuhkan upaya khusus untuk menambah pendapatan usahataninya sehingga menjadi tidak miskin lagi. Tingkat keberhasilan dari upaya tersebut sehingga dapat terukur dan tepat sasaran diperlukan model pemberdayaan petani ubikayu bagi pengambil kebijakan dalam memfokuskan perhatian pada perbaikan kondisi hidup orang miskin. Penelitian ini bertujuan untuk :

1. Menganalisis pendapatan, saluran pemasaran dan margin tataniaga usahatani ubikayu di Kabupaten Sukabumi. 
2. Menganalisis nilai tambah pengolah ubikayu menjadi tepung aci dan komponen yang berpengaruh pada nilai tambah.

3. Meyusun model pemberdayaan ubikayu melalui pola klaster sistem agribisnis ubikayu.

Delapan sasaran pembangunan atau Millenium Development Goals (MDGs) menjadi arah dalam kebijakan dan program pembangunan di Indonesia yaitu pengentasan kemiskinan dan kelaparan yang ketercapaiannya dapat dicapai tahun 2015. Upaya percepatan dalam mencapaianya perlu ditunjang dengan meningkatkan pendapatan petani ubikayu melalui strategi penerapan pola klaster. Berdasarkan hal-hal diatas, maka penelitian tentang pengentasan kemiskinan sistem agribisnis ubikayu sangat penting dan strategis.

\section{METODE PENELITIAN}

\section{Jenis Penelitian}

Jenis penelitian ini adalah explorative and developmental research. Penelitian eksploratif dilakukan guna memperoleh Deskripsi profil usahatani ubikayu, kegiatan pasca panen, nilai tambah dan industri pengolahannya, kegiatan produktif lainnya.Developmental research dilaksanakan guna mengembangkan model pengentasan kemiskinan untuk melihat efektifitasnya dalam proses meningkatkan pendapatan petani.

\section{Lokasi Penelitian}

Lokasi penelitian dipusatkan di wilayah sentra produksi ubikayu di Kabupaten Sukabumi dan di lokasi industri pengolahannya. Pemilihan lokasi ini dilakukan dengan pertimbangan luas areal dan produksi yang relatif tinggi di daerah sentra produksi ubikayu dan keberadaan lokasi industri pengolahan produk ubikayu di Sukabumi.

Berdasarkan pertimbangan Data luas tanam, luas panen dan produktivitas diperoleh informasi musin tanam 2010, berdasarkan pertimbangan metode sampling maka dipilih tiga lokasi penelitian yaitu Desa Warungkiara Kecamatan Warungkiara, Desa Bojongtipar Kecamatan Jampang Tengah dan Desa Purabaya Kecamatan Purabaya.

\section{Waktu Penelitian}

Penelitian dilaksanakan dua tahap. Tahap pertama dimulai Bulan Pebruari 2012 sampai Nopember 2012. Tahap kedua dilaksanakan awal Tahun 2013 sampai Nopember 2013.

\section{Responden Penelitian}

Responden utama dalam penelitian ini yaitu masyarakat miskin yang bermatapencaharian dengan berusahatani ubikayu di wilayah sentra produksi ubikayu, sedangkan responden untuk industri pengolah yaitu pengelola industri. Adapun responden tambahan sebagai nara sumber yaitu aparat pemerintah dan perangkat desa serta pelaku tataniaga.

Metode sampling untuk menentukan responden dilakukan dengan metode two stage cluster random sampling. Metode ini dilakukan dengan cara dua tahap yaitu tahap pertama menentukan kecamatan terpilih sentra produksi ubikayu dan pertimbangan produktivitas lahan. Tahap kedua menentukan desa terpilih berdasarkan pertimbangan jumlah penduduk miskin terbanyak dan atau keberadaan industri pengolahan ubikayu. Selanjutnya dari desa terpilih dipilih secara acak masing masing desa dipilih minimal 30 responden.

Berdasarkan data luas tanam, luas panen dan produktivitas diperoleh informasi luas tanam ubikayu terluas yaitu Kecamatan Warungkiara, luas panen terbanyak yaitu Kecamatan Jampang Tengah dan produktivitas rendah pada Kecamatan Purabaya. Selanjutnya dipilih desa dengan jumlah penduduk miskin terbesar dan mempertimbangkan keberadaan industri pengolah dari setiap kecamatan terpilih yaitu Desa Warungkiara di Kecamatan Warungkiara, Desa Bojongtipar di Kecamatan Jampang Tengah dan Desa Purabaya di Kecamatan Purabaya. Dua desa yaitu Desa Bojongtipar dan Desa Purabaya dipilih masingmasing 30 responden dan Desa Warungkiara 31 responden. Jumlah total responden petani sebanyak 91 responden. Responden industri pengolah ubikayu dipilih secara purposive sebanyak dua pabrik untuk setiap petani yang terpilih dalam mengolah hasil produksinya.

\section{Metode Pengumpulan Data}

Data primer diperoleh dengan menggunakan teknik wawancara langsung dengan 
menggunakan kuesioner dan dengan melakukan observasi di lapangan. Selain pengumpulan data primer juga dikumpulkan data, informasi dan karakteristik eksternal seperti dukungan pemerintah, ancaman luar, keterkaitan aktivitas ekonomi dan lain-lain.

\section{Metode Analisis Data}

Data yang telah dikumpulkan diolah secara kuantitatif, lalu ditampilkan dalam bentuk tabel. Selanjutnya dipetakan komponen ekonomi yang menggambarkan permasalahan dan potensi pendapatan dan potensi lain yang berkembang di masyarakat. Selain data kuantitatif dilakukan pendekatan kualitatif yang dimaksud disini adalah metode penelitian yang dipakai untuk melakukan pemetaan sosial, pemetaan terhadap pranata-pranata sosial yang tumbuh dan berkembang serta keterkaitan diantara lembaga yang ada.

\section{HASIL DAN PEMBAHASAN}

\section{Kegiatan Usahatani Ubikayu}

Keragaan Kegiatan usahatani Ubikayu dianalisis untuk mengetahui gambaran umum tentang usahatani Ubikayu di lokasi Penelitian. Analisis kegiatan Usahatani Ubikayu dilakukan dengan mengidentifikasi penggunaan input, teknik budidaya, dan output yang dihasilkan pada usahatani Ubikayu.

\section{Penggunaan Input, Output Usahatani Ubikayu Petani, Harga dan Pendapatan}

Hasil dari proses produksi usahatani ubikayu adalah berupa ubikayu segar, dan biasanya dihitung dengan menggunakan satuan kilogram umbi kupas. Berikut ini disajikan data input, ouput, biaya dan pendapatan usahatani ubikayu.

\section{Analisis Pemasaran Ubikayu}

Analisis pemasaran Ubikayu diawali dari petani sebagai produsen hingga konsumen akhir atau pabrik pengolah. Analisis pemasaran ubikayu dilihat dari saluran pemasaran, fungsi-fungsi pemasaran dan margin pemasaran.

Saluran Pemasaran dan Fungsi Pemasaran. Saluran pemasaran Ubikayu di lokasi penelitian melibatkan beberapa lembaga pemasaran yaitu tengkulak atau pedagang pengumpul desa. Secara umum terdapat satu saluran pemasaran untuk Ubikayu yang terjadi di Desa Bojongtipar dapat dilihat pada Gambar. 1

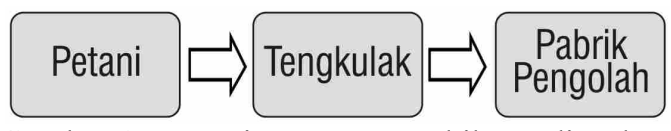

Gambar.1. Rantai Pemasaran Ubikayu di Lokasi Penelitian

Tabel 1. Rata-rata Biaya Penerimaan, Biaya dan Pendapatan Usahatani Ubikayu per Hektar MT 2011/2012 (Rp/hektar)

\begin{tabular}{llcccc}
\hline No & \multicolumn{1}{c}{ Input } & Satuan & $\begin{array}{c}\text { Harga } \\
\text { Satuan }\end{array}$ & Volume & Nilai \\
\hline A & \multicolumn{1}{c}{$\begin{array}{c}\text { Penerimaan } \\
\text { Biaya }\end{array}$} & $\mathrm{kg}$ & 905 & 17.085 & 15.461 .925 \\
$\mathrm{~B}$ & \multicolumn{1}{c}{ (sewa) } & $\mathrm{Ha} / \mathrm{th}$ & 316.667 & 1 & 2.583 .333 \\
1. & Lahan & & & \\
2 & Bibit (batang) & Batang & 60,1 & 9463 & $568.726,3$ \\
3 & Pupuk & $\mathrm{Kg}$ & & & \\
& Urea & & 2324 & 258 & 599.592 \\
& KCl & & 3000 & 277 & 831.000 \\
& Poska & & 2875 & 152 & 437.000 \\
& TSP & & 2742 & 257 & 704.694 \\
& Pupuk Kandang & Karung & 7524 & 211 & 1.587 .564 \\
& Total Biaya Pupuk & & & & 4.159 .850 \\
4 & Tenaga Kerja & HOK & 25.230 & 117,5 & $2.966 .291,1$ \\
& Total Biaya & & & & $10.278 .200,3$ \\
C & Pendapatan & Rp & & & $5.183 .724,7$ \\
\hline Sumber : Analisis Data Primer & & &
\end{tabular}


Himmatul M. dan Ahmad Syarbaini: Model Pemberdayaan Petani Ubikayu Melalui ...

Tabel 2. Fungsi Pemasaran yang dilakukan oleh Lembaga Pemasaran

\begin{tabular}{|c|c|c|c|}
\hline No & $\begin{array}{l}\text { Lembaga } \\
\text { Pemasaran }\end{array}$ & $\begin{array}{c}\text { Fungsi } \\
\text { Pemasaran }\end{array}$ & Aktifitas \\
\hline 1 & Petani & Pertukaran & Penjualan \\
\hline \multirow[t]{3}{*}{2} & Tengkulak & Pertukaran & Pembelian dan penjualan \\
\hline & & Fisik & $\begin{array}{l}\text { Pencabutan, Pengupasan, Pengemasan dan pengangkutan } \\
\text { Ubikayu ketempat penjualan }\end{array}$ \\
\hline & & Fasilitas & Informasi pasar dan penjualan \\
\hline \multirow[t]{2}{*}{3} & Pabrik Pengolah & Pertukaran & Pembelian dan Penjualan \\
\hline & & Fisik & $\begin{array}{l}\text { Pembersihan, Penggilingan, Pengendapaan, penjemuran, } \\
\text { pengemasan }\end{array}$ \\
\hline
\end{tabular}

Tabel 3. Nilai Margin Pemasan Ubikayu

\begin{tabular}{llc}
\hline No & \multicolumn{1}{c}{ Unsur Margin } & Rata-rata (Rp) \\
\hline 1 & Harga Jual Petani & 905 \\
2 & Harga Beli Tengkulak & 905 \\
& -Biaya pengupasan & 126,67 \\
& -Biaya pengangkutan & 46,67 \\
& -Pungli & 25 \\
& -Biaya Transportasi & 150 \\
3 & Keuntungan & 146,67 \\
4 & Margin & 495 \\
5 & Harga jual Tengkulak & 1.400 \\
\hline
\end{tabular}

Sumber : Analisis Data Primer

Tabel 4. Rata-rata Nilai Tambah Ubikayu Satu Kali Produksi Pengolah Aci

\begin{tabular}{|c|c|c|c|}
\hline No & Keterangan & Perhitungan & Rata-rata \\
\hline 1 & Output (Kg/proses produksi) & A & 500 \\
\hline 2 & Input Ubikayu (Kg/proses produksi) & $\mathrm{B}$ & 1000 \\
\hline 3 & Tenaga Kerja (HOK/proses produksi) & $\mathrm{C}$ & 5,625 \\
\hline 4 & Faktor konversi & $\mathrm{D}=\mathrm{A} / \mathrm{B}$ & 0,5 \\
\hline 5 & Koefisien tenaga kerja & $\mathrm{E}=\mathrm{C} / \mathrm{B}$ & 0,0056 \\
\hline 6 & Harga Ouput (Rp/ Kg) & $\mathrm{F}$ & 5250 \\
\hline 7 & Upah tenaga kerja (Rp/HOK) & G & 32.500 \\
\hline 8 & Harga bahan baku (Rp/Kg) & $\mathrm{H}$ & 1.400 \\
\hline 9 & Sumbangan input lain $(\mathrm{Rp} / \mathrm{kg})$ & I & 100 \\
\hline 10 & Nilai Output (Rp) & $\mathrm{J}=\mathrm{D} \times \mathrm{F}$ & 2.625 \\
\hline \multirow[t]{2}{*}{11} & a. Nilai Tambah $(\mathrm{Rp} / \mathrm{kg})$ & $\mathrm{K}=\mathrm{J}-\mathrm{H}-\mathrm{I}$ & 1.125 \\
\hline & b. Rasio Nilai tambah (\%) & $\mathrm{L}=(\mathrm{K} / \mathrm{J}) \times 100 \%$ & 42,86 \\
\hline \multirow[t]{2}{*}{12} & a. Pendapatan tenaga kerja $(\mathrm{Rp} / \mathrm{kg})$ & $\mathrm{M}=\mathrm{E} \times \mathrm{G}$ & 182 \\
\hline & b. Bagian tenaga kerja (\%) & $\begin{array}{l}\mathrm{N}=(\mathrm{M} / \mathrm{K}) \\
100 \%\end{array}$ & $16,17 \%$ \\
\hline \multirow[t]{2}{*}{13} & a. Keuntungan $(\mathrm{Rp} / \mathrm{Kg})$ & $\mathrm{O}=\mathrm{K}-\mathrm{M}$ & 943 \\
\hline & b. Tingkat keuntungan $(\%)$ & $\begin{array}{l}\mathrm{P}=(\mathrm{O} / \mathrm{K}) \times 100 \\
\%\end{array}$ & $83,82 \%$ \\
\hline \multirow[t]{5}{*}{14} & Margin (Rp/Kg) & $\mathrm{Q}=\mathrm{J}-\mathrm{H}$ & 1.225 \\
\hline & a. Pendapatan tenaga kerja (\%) & $\mathrm{R}=(\mathrm{M} / \mathrm{Q}) \mathrm{x}$ & $14,86 \%$ \\
\hline & b.Sumbangan input lain (\%) & $100 \%$ & $8,16 \%$ \\
\hline & c. Keuntungan pengolah (\%) & $S=(I / Q) \times 100 \%$ & $76,98 \%$ \\
\hline & & $\begin{array}{l}\mathrm{T}=(\mathrm{O} / \mathrm{Q}) \quad \mathrm{x} \\
100 \%\end{array}$ & \\
\hline
\end{tabular}

Sumber : Analisis Data Primer 
Pelaku pemasaran melaksanakan fungsi-fungsi pemasaran berupa fungsi pertukaran, fungsi fisik, dan fungsi fasilitas.

Biaya Pemasaran dan Margin. Besarnya biaya pemasaran dan nilai margin pemasaran Ubikayu pada saluran Ubikayu Petani dapat dilihat pada Tabel 3. Berdasarkan Tabel 3, menunjukkan bahwa keuntungan tengkulak adalah Rp. 146,67,- sedangkan nilai total margin adalah sebesar Rp 495,- yang merupakan selisih antara harga jual tengkulak dengan harga jual dari petani.

\section{Analisis Nilai Tambah Ubikayu}

Analisis nilai tambah pengolahan ubikayu dilakukan dengan menggunakan metode Hayami disajikan pada Tabel 4 .

\section{Output, Input dan Harga}

Rata-rata penggunaan bahan baku berupa ubikayu dalam proses pembuatan aci pada responden pabrik pengolah ubikayu adalah 1000 kilogram bahan baku per proses produksi. Hasil produksi dari pengolahan rata-rata bahan baku per proses produksi adalah 500 kilogram produk utama berupa tepung tapioca/aci

Pabrik Pengolah aci memperoleh bahan baku dari petani ubikayu di sekitar desa melalui para tengkulak. Tenaga kerja adalah jumlah orang yang dibutuhkan dalam proses produksi. Ketersediaan tenaga kerja mutlak dibutuhkan dalam proses produksi. Rata-rata kebutuhan tenaga kerja dalam satu kali proses produksi aci adalah 5,625 HOK. Satu HOK adalah delapan jam kerja atau satu hari kerja orang dewasa. Nilai faktor konversi yaitu perbandingan antara output dengan input. Nilai faktor konversi untuk produk aci adalah jumlah output dibagi dengan input yang digunakan. Rata-rata nilai faktor konversi adalah sebesar 0,5. Nilai faktor konversi menunjukkan bahwa setiap 100 kilogram ubikayu mampu menghasilkan 50 kilogram aci.

\section{Pendapatan dan Keuntungan}

Besarnya pendapatan yang diterima oleh tenaga kerja per proses produksi yaitu Rp 32.500 per HOK. Besarnya upah tersebut diperoleh dari upah riil yang diterima oleh tenaga kerja secara keseluruhan pada masing-masing proses produksi. Jadi besarnya pendapatan yang diterima oleh tenaga kerja langsung dari pengolahan satu kilogram ubikayu menjadi aci adalah $\mathrm{Rp} 182$ per kilogram, dengan bagian tenaga kerja sebesar 16,17 persen dari nilai tambah.

Hasil perhitungan nilai tambah yang diperoleh dari pengolahan ubikayu menjadi aci menunjukkan bahwa besarnya rata-rata nilai tambah pada pengolah aci adalah Rp 1.125 per kilogram bahan baku ubikayu. Perhitungan nilai tambah bertujuan untuk mengetahui besarnya nilai tambah dalam satu kilogram ubikayu setelah diolah menjadi aci. Hal tersebut bertujuan sebagai bahan informasi bagi pengolah aci dalam meningkatkan usahanya.

Besarnya nilai tambah tergantung pada biaya yang dikeluarkan meliputi biaya pembelian bahan baku sebesar Rp 1.400 per kilogram dan sumbangan input lain sebesar Rp 100 per kilogram. Sumbangan input lain terdiri dari seluruh biaya variabel kecuali biaya bahan baku dan upah tenaga kerja. Input lain di dalamnya mencakup biaya pembelian bahan bakar mesin giling dan biaya transportasi.

Rasio nilai tambah ubikayu per proses produksi pada pengolah aci adalah sebesar 42,86 persen. Rata-rata keuntungan yang diperoleh dari proses pembuatan aci yaitu sebesar Rp 94,-3 per kilogram atau sebesar 83,82 persen.

\section{Balas Jasa Untuk Faktor Produksi}

Balas jasa faktor produksi terdiri atas balas jasa untuk faktor produksi tenaga kerja, input lain, dan tingkat keuntungan. Margin merupakan selisih harga atau nilai produk dengan nilai input bahan baku. Margin akan didistribusikan untuk imbalan tenaga kerja, sumbangan input lain, dan keuntungan perusahaan.

Rata-rata margin dari produksi aci adalah sebesar Rp 1.225 per kilogram ubikayu, yang terdiri atas 14,86 persen pendapatan tenaga kerja, 8,16 persen sumbangan input lain, dan 76,98 persen keuntungan pengolah aci.

\section{Model Pemberdayaan Petani ubikayu}

Penelitian ini menyajikan alternatif model pemberdayaan dengan membagi ke dalam tiga unsur pokok yaitu petani/kelompok tani (Poktan), sistem agribisnis dan unsur kelembagaan (Lihat Gambar 2) 
Himmatul M. dan Ahmad Syarbaini: Model Pemberdayaan Petani Ubikayu Melalui ...

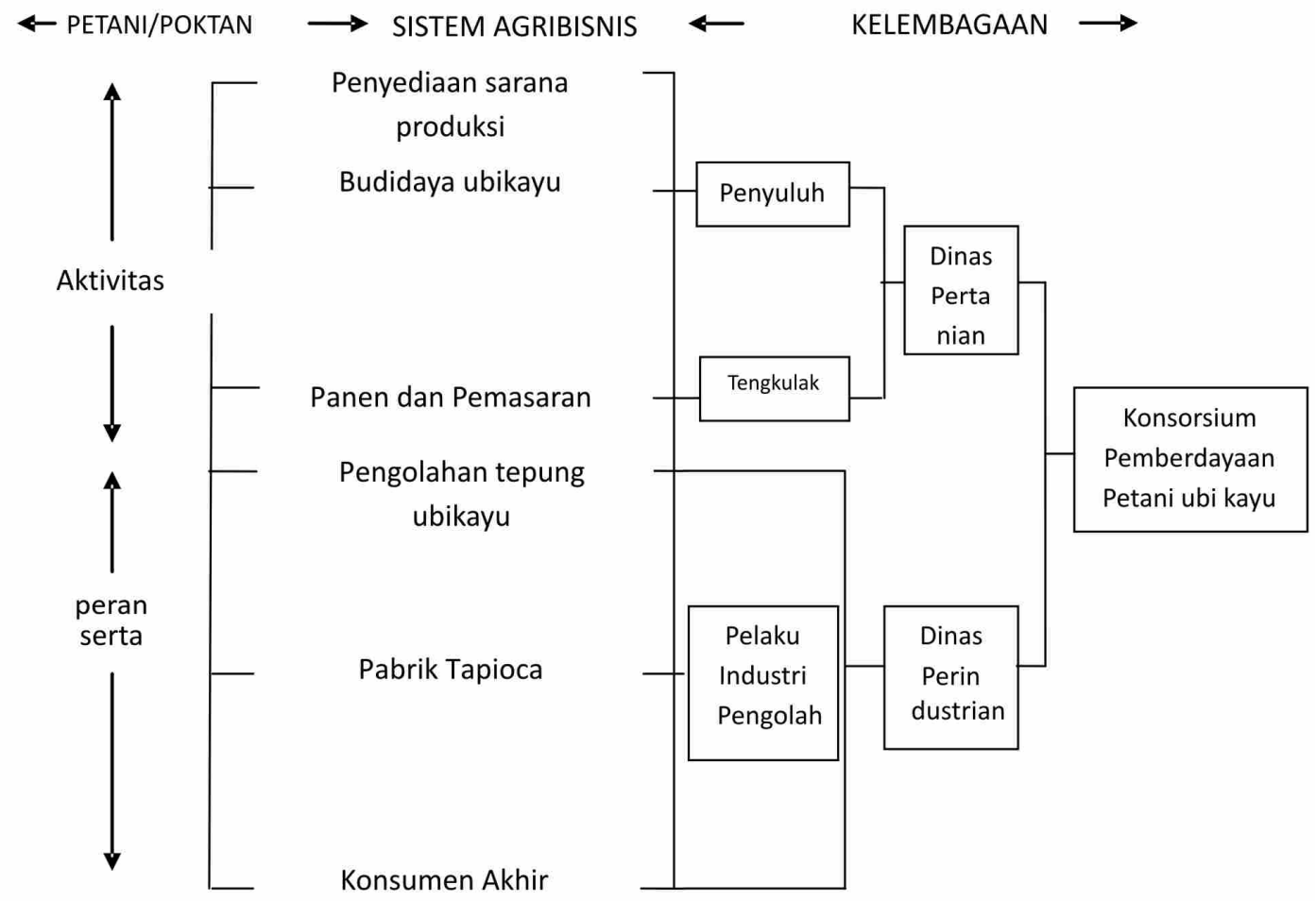

Gambar 2. Model Pemberdayaan Petani Ubikayu Terintegrasi

\section{KESIMPULAN DAN SARAN}

\section{Kesimpulan}

Berdasarkan tujuan penelitian dan hasil penelitian, maka dapat ditarik kesimpulan sebagai berikut:

1. Pendapatan usahatani ubikayu per hektar sebesar Rp 5.183.724,7 berdasarkan pendapatan yang diperhitungkan.

2. Saluran pemasaran ubikayu petani terdiri dari satu saluran pemasaran, yaitu petani menjual ke tengkulak dan dari tengkulak dijual ke konsumen akhir atau pabrik pengolah aci. Margin pemasaran adalah Rp. 495,00 diperoleh dari selisih harga jual tengkulak dengan harga jual dari petani.

3. Nilai Tambah yang dihasilkan oleh pengolah aci adalah sebesar Rp. 1.125 per kilogramnya.. Hal yang mempengaruhi besarnya nilai tambah tergantung dari harga output atau harga aci dari ubikayu, biaya pembelian bahan baku dan biaya sumbangan input lain.

4. Model Pemberdayaan Petani Ubikayu terdiri dari tiga komponen utama yaitu Petani/Kelompok Tani, Sistem Agribisnis dan Kelembagaan. Keberhasilan model ini sangat ditentukan oleh peranan petani, penyuluh dan tengkulak serta lembaga konsorsium yang mengoordinir lembaga yang terlibat.

\section{Saran}

Kunci keberhasilan model pemberdayaan Klaster ini teletak pada besarnya tingkat integrasi antara agribusnis hulu dengan agribisnis hilir. Integrasi ini akan memberikan nilai pada curahan kerja yang bertambah dan perolehan nilai tambah dan margin pemasaran dari indutri olahannya. Peningkatan pendapatan ini sebagai akibat kenaikan produksi, produktivitas serta kualitas, standarisasi dan grading yang sesuai dengan kebutuhan industri olahannya. Mengingat peran tengkulak sangat besar maka sedapat mungkin memberi perhatian khusus dan pembinaan yang intensif sehingga dapat menjembatani ketercapaian proses usahatani ubikayu yang berorientasi pada kebutuhan pasar. Integrasi dapat dilakukan melalui pendirian lembaga khusus yang menangani kegiatan usaha berbasis komoditas ubikayu. 


\section{DAFTAR PUSTAKA}

Badan Pusat Statistik. 2009. Indikator Kesejahteraan Sosial Rakyat tahun 2009. Badan Pusat Statistik. Jakarta.

Angka . Bandung.

Angka. Bandung.

----------. 2011. Kabupaten Sukabumi dalam Angka. Sukabumi

Daud, M. 2010. Pendekatan Pola Kluster Singkong. Bahan Diskusi Rountable Kadin Pusat Jakarta.

Dwiari, S. R. 2008. Teknologi Pangan. Jakarta: Pusat Perbukuan, Departemen Pendidikan Nasional, 2008. http://www.kabupatensukabumi.go.id.diak ses 2012

Komunitas Petani. 2008. http://mahmudisiwi.net/komunitas-petani. [diakses tahun 2011].
Musyadar, A. 2002. Analisis Investasi usaha Pertanian. STPP. Bogor.

Nenni.2000. Analisis Nilai Tambah Prospek Pengembangan Industri Pengolahan ubikayu. Fakultas Pertanian Universitas Djuanda. Bogor.

Pambudy, R. 1999. Kumpulan Pemikiran : Bisnis dan Kewirausahaaan dalam Sistem Agribisnis. Cetakan pertama. Penerbit Wirausaha Muda. Bogor

Produk Singkong. 2010. http://prapanca21.wordpress.com. (Diakses tahun 2010).

Saragih, B. 1999. Suara dari Bogor. Membangun Sistem Agribisnis. Sucofindo. Jakarta.

Sukartawi. 1996. Ilmu Usahatani. Rajawali Press. Jakarta.

Sumodiningrat, G. 1999. Pemberdayaan Masyarakat dan JPS. PT Gramedia Pustaka Utama. Jakarta. 